FEDERAL RESERVE BANK OF SAN FRANCISCO

WORKING PAPER SERIES

\title{
A Quarterly, Utilization-Adjusted Series on Total Factor Productivity
}

\author{
John Fernald \\ Federal Reserve Bank of San Francisco
}

April 2014

Working Paper 2012-19

http://www.frbsf.org/economic-research/publications/working-papers/2012/19/

John Fernald. 2014. “A Quarterly, Utilization-Adjusted Series on Total Factor Productivity” Federal Reserve Bank of San Francisco Working Paper 2012-19. https://doi.org/10.24148/wp2012-19

The views in this paper are solely the responsibility of the author and should not be interpreted as reflecting the views of the Federal Reserve Bank of San Francisco or the Board of Governors of the Federal Reserve System. 


\title{
A Quarterly, Utilization-Adjusted Series on Total Factor Productivity
}

\author{
John Fernald* \\ Federal Reserve Bank of San Francisco \\ April 2014
}

\begin{abstract}
This paper describes a real-time, quarterly growth-accounting database for the U.S. business sector. The data on inputs, including capital, are used to produce a quarterly series on total factor productivity (TFP). In addition, the dataset implements an adjustment for variations in factor utilization - labor effort and the workweek of capital. The utilization adjustment follows Basu, Fernald, and Kimball (BFK, 2006) as updated in Basu, Fernald, Fisher, and Kimball (BFFK, 2013). Using relative prices and input-output information, the series are also decomposed into separate TFP and utilization-adjusted TFP series for equipment investment (including consumer durables) and "consumption" (defined as business output less equipment and consumer durables).
\end{abstract}

JEL Codes: E22, E23, O41, O47, Keywords: Total factor productivity, cyclical productivity, multi-sector growth models

* Contact email: john.fernald@sf.frb.org. The data described in this paper are available at http://www.frbsf.org/economics/economists/jfernald/quarterly tfp.xls. I thank several excellent research assistants who have worked with me on this project, most notably Kyle Matoba (who wrote and rewrote large portions of the code and found sensible solutions to a range of practical problems), as well as Titan Alon, Kuni Natsuki, and David Thipphavong. This draft is updated intermittently as I make improvements in methodology. For helpful discussions of various aspects of the implementation, I especially thank Susanto Basu, Ryan Forshay, Bob Hall, and Bart Hobijn. In addition, I thank other colleagues at the San Francisco Fed as well as seminar participants where related papers were presented for providing helpful comments on the dataset. The views in this paper are solely the responsibility of the authors and should not be interpreted as reflecting the views of the Federal Reserve Bank of San Francisco or the Board of Governors of the Federal Reserve System. 
Academic researchers and policymakers frequently want high-frequency measures of technology. These measures might be fed into models, or used to understand the effects of technology shocks on the economy, or to assess trends in potential output. Relatively crude measures of the Solow residual are easy to construct. But more careful quarterly measures that better correspond to theoretical concepts are more difficult to construct. With annual data, in contrast, there are several relatively high-quality sources of aggregate and/or industry total factor productivity (TFP), including the "multifactor productivity" measures produced by the Bureau of Labor Statistics (BLS), various measures produced by Dale Jorgenson and collaborators, ${ }^{1}$ and the EU KLEMS project.

This paper describes a new real-time, quarterly growth-accounting database for the U.S. business sector. There are three major advantages relative to naïve or crude Solow residuals. First, the data on inputs, including both capital and labor, apply the careful growth-accounting methods used by the BLS, Jorgenson, EU-KLEMS, and others.

Second, the quarterly dataset implements an adjustment for variations in factor utilization that follows Basu, Fernald, and Kimball (BFK, 2006). (As of March 2014, the estimates have been updated using Basu, Fernald, Fisher, and Kimball (2014), which is the same model and method, but more recent data.) After all, even the most careful measure of raw TFP does not provide a quarterly measure of technology change. A major reason is variations in factor utilization-labor effort and the workweek of capital.

Third, using relative prices and input-output information, the series are also decomposed into separate TFP and utilization-adjusted TFP series for equipment investment (including

\footnotetext{
${ }^{1}$ For references and available datasets, see http://scholar.harvard.edu/jorgenson/data (accessed September 26, 2012).
} 
consumer durables) and "consumption" (defined as business output less equipment and consumer durables). Because of the utilization-adjustment, the resulting relative technology series are not simply equated to relative prices (the default in much of the macro literature that follows Greenwood, Hercowitz, and Krusell, 1997).

In terms of the first advantage, careful growth accounting controls for heterogeneity across workers and types of capital. Consider labor input. Simple hours worked data (e.g., from the BLS productivity and cost release) combine hours of construction workers, fast-food cashiers, auto mechanics, dentists, engineers, CEOs, and so forth. These workers have very different wage rates which, presumably, correspond to differences in marginal products. Similarly, a computer (which provides a service flow for only three or four years) needs to have a higher marginal product than an office building (which might provide services for 50 years). The dataset weights different inputs using actual or estimated relative factor prices to control for these differences in implied marginal products.

Note that this heterogeneity in the data might matter even for researchers with interest in aggregate models with a representative agent and a single type of capital. For example, labor composition (or quality) fluctuates a fair amount at high frequency-e.g., in recessions, labor quality systematically rises, since workers with lower skills and education are more likely to lose their jobs. Unless measured TFP controls for labor composition then, relative to underlying technology, measured TFP will be biased up in recessions.

Economic theory suggests that another form of heterogeneity is potentially important: Heterogeneity by type of final product. Considerable recent literature has focused on so-called investment-specific technical change (see, for example, Greenwood, Hercowitz, and Krusell, 1997; and Basu, Fernald, Fisher, and Kimball, BFFK, 2013). I use relative prices to decompose 
TFP for the aggregate economy into TFP for equipment and consumer durables, and into TFP for “consumption" (everything other than equipment and consumer durables).

As with the standard TFP residual, these measures are not necessarily good measures of technological change from quarter to quarter. Indeed, an important caveat is that Fisher (2006) and BFFK find that pass-through from (fully corrected) relative technology shocks to relative prices is very slow. However, BFFK find that uncorrected measures of relative TFP are more closely related to relative prices - almost as a measure of accounting. ${ }^{2}$ Importantly, the utilization adjustment corrects for a quantitatively important wedge between measured relative TFP and underlying relative technology.

The adjustment for variable utilization in the quarterly series follows Basu, Fernald, Fisher, and Kimball (BFFK, 2013). (Previous versions of this quarterly series followed Basu, Fernald, and Kimball, BFK, 2006). BFFK and BFK sought to adjust for a range of nontechnological factors that affect measured TFP, of which variations in the utilization margin-i.e., the intensity margin for the workweek of capital and labor effort — are only one. Other potential corrections include allowing for deviations from perfect competition and for various reallocation effects. BFFK update the earlier BFK results, and estimate utilization imposing constant returns, which is more consistent with the current paper (though that turns out not to be a major issue for utilization). These estimates rely on annual data, where there are rich industry-level details on output and intermediate-input flows, as well as on industry investment. These data are not available quarterly. Nevertheless, the utilization-adjusted quarterly series is an improvement over more "naïve" measures of TFP as a high-frequency indicator of technological change.

\footnotetext{
${ }^{2}$ The intuition comes from the dual approach to growth accounting: TFP can equivalently be defined as growth in real factor prices. If all firms faced the same factor prices and had the same factor shares, then real factor prices differ only because of output prices. See Basu, Fernald, Fisher, and Kimball (2011).
} 
Finally, this series incorporates output information from both the income and product sides of the national accounts. Nalewaik (2011) argues that both measures are informative about economic activity, particularly around business-cycle turning points. The default TFP measures here weight the two approaches equally. ${ }^{3}$

Section I defines TFP, labor and capital inputs, and utilization. It discusses the method I follow to decompose TFP into investment and consumption components, and then discusses the BFK approach to controlling for variable utilization. Section II summarizes the key data sources used to construct quarterly TFP. Section III provides a detailed discussion of data sources. Section IV compares the quarterly TFP series to the well known annual BLS multifactor productivity series.

\section{Method}

\section{Aggregate TFP}

Suppose we model aggregate activity with an aggregate production function: ${ }^{4}$

$$
Y_{t}=F\left(Z_{t} \cdot K\left(K_{1, t-1}, K_{2, t-1}, . . K_{J, t-1}\right), E_{t} \cdot L\left(H_{1, t}, H_{2, t}, \ldots H_{N, t}\right), A_{t}\right)
$$

$K$ is capital input, which is an aggregate of the service flow, $K_{j, t-1}$, from the $J$ types of capital (e.g., computers, transportation equipment, structures, and land); the service flow in period $t$ is proportional to the stock of that type of capital at the end of period $t-1 . L$ is labor input, which is an aggregate of the hours worked, $H_{j}$, by $N$ types of workers (e.g., female 40year-old college-educated professionals, male 22-year old high-school dropouts, and so forth). $Z$ is capital utilization (e.g., the average workweek of capital) and $E$ is effort per unit of labor. $A$ is technological change.

\footnotetext{
${ }^{3}$ I thank Bob Hall for encouraging the incorporation of income-side information.

${ }^{4}$ See Basu and Fernald (2001) for a discussion of the more general case in which an aggregate constantreturns production function may not exist and how, in practice, the effects show up in the aggregate Solow residual.
} 
The representative firm takes capital rental rates, $R_{j}$, and wages, $W_{n}$, as given and charges a markup $\mu$ of price over marginal cost. The first-order conditions for cost minimization imply that output elasticities are a markup over cost shares, i.e., $\left(\partial Y_{t} / K_{j, t}\right)\left(K_{j, t} / Y_{t}\right)=\mu\left(R_{j, t} K_{j} / P_{t} Y_{t}\right)=\mu \gamma_{j, t}$ and $\left(\partial Y_{t} / H_{n, t}\right)\left(H_{n, t} / Y_{t}\right)=\mu\left(W_{n} H_{n} / P_{t} Y_{t}\right)=\mu \beta_{n, t} \cdot \gamma_{j, t}$ is the share of capital of type $j$, where $\sum_{j} \gamma_{j, t}=\alpha_{t}$, and $\beta_{n, t}$ is the share of labor of type $n$, where (with zero economic profits, which is consistent with markups that just cover fixed costs) $\sum_{n} \beta_{n, t}=\left(1-\alpha_{t}\right)$. In the data, we will take capital's share $\alpha_{t}$ as a residual, which enforces that capital and labor's shares sum to one. In this setup, differences in factor prices are assumed to imply differences in marginal products.

Composition-adjusted growth in capital and labor input are:

$$
\begin{aligned}
\Delta \ln K_{t} & \equiv \sum_{j}\left(\gamma_{j, t} / \alpha_{t}\right) \Delta \ln K_{j, t-1} \\
\Delta \ln L_{t} & =\sum_{n}\left(\beta_{n, t} /\left(1-\alpha_{t}\right)\right) \Delta \ln H_{n, t} \equiv \Delta \ln Q_{t}+\Delta \ln H_{t}, \text { where } \Delta \ln H_{t}=\Delta \ln \sum_{n} H_{n, t}
\end{aligned}
$$

These definitions weight different types of inputs using marginal products. Markups hit all factors equally, so that they do not enter these definitions. Labor input is explicitly decomposed into raw hours worked, $H$, and "quality," $Q$, where $Q$ is implicitly defined in the second equation as the difference between growth in labor input and growth in raw hours. The reason for explicitly breaking out quality and quantity of labor is that they come from different sources that rely on different methods. ${ }^{5}$ Differentiating the production function and dropping time subscripts (for simplicity) yields:

$$
\Delta \ln Y=\mu(\alpha \Delta \ln K+(1-\alpha) \Delta \ln (L))+\Delta \ln U+\Delta \ln A
$$

${ }^{5}$ Raw hours worked are (relatively) easy to measure, and the BLS reports those quarterly. In contrast, the mix of workers, and their relative wages (which are used as proxies for relative marginal products)need to be estimated from smaller samples from the Current Population Survey. In addition, there are several methods of estimating relative marginal products for different types of workers from those data. 
where $\Delta \ln U \equiv \mu[\alpha \Delta \ln Z+(1-\alpha) \Delta \ln E]$. We normalize the elasticity of $\mathrm{F}$ with respect to technology, A, to equal unity.

We define TFP growth (aka, the Solow residual) as:

$$
\Delta \ln T F P \equiv \Delta \ln Y-\alpha \Delta \ln K-(1-\alpha) \Delta \ln L
$$

Given an estimate of the contribution of utilization, $\Delta \ln U$, utilization-adjusted TFP growth is:

$$
\Delta \ln T F P-U t i l=\Delta \ln T F P-\Delta \ln U
$$

With perfect competition, so $\mu=1, \Delta \ln T F P$-Util equals technology growth, $\Delta A$.

In the context of a specific model, TFP is often defined using (1), i.e., as the multiplicative technology term in the production function, $A$. Under standard conditions (constant returns to scale, perfect competition, and identical factor prices for all producers), the statistical definition corresponds to the multiplicative technology term in the model. Hulten (1978) shows that—in a model with heterogeneous, constant-returns, perfectly competitive producers facing identical factor prices - this definition of aggregate TFP can be interpreted as the outward shift in society's aggregate production possibilities frontier.

However, in some models (e.g., with markups, possibly heterogeneous across producers, of price above marginal cost, or with factor adjustment costs that lead the shadow cost of inputs to differ across firms), aggregate TFP and aggregate technology are not the same — even in the absence of variable factor utilization; see, for example, Basu and Fernald (2001). Even then, the statistical definition of $\triangle \ln T F P$ is still an object that can be defined in the model and compared with the data.

Any failures of aggregation (so that there is no aggregate production function of the form posited here) will, of course, show up in utilization-corrected TFP growth. Similarly, if observed factor shares do not equal output elasticities — as in the case with imperfect competition — then 
those effects will also show up in utilization-adjusted TFP growth. Using detailed industry data at an annual frequency, BFK and BFFK control for these factors to develop a "purified" technology measure. As noted above, these necessary data are available only with a long lag, and are not available quarterly.

\section{$\underline{\text { Utilization }}$}

Basu, Fernald, and Kimball (2006) and Basu, Fernald, Fisher, and Kimball (2013) seek to estimate "purified" Solow residuals by controlling for non-technological factors that could affect these residuals. In particular, BFK estimate a Hall (1990)-style regression on industry-level data, which allows for non-constant returns to scale and imperfect competition as well as variable factor utilization. In quarterly data, it is not possible to implement the full BFK estimation. However, we can implement part of it, in order to decompose TFP growth into utilization change, $\Delta \ln U$, and utilization-adjusted TFP, $\Delta \ln A^{T F P}$.

A large literature suggests that unobserved variations in factor utilization are important over the business cycle. ${ }^{6}$ For example:

- Firms hoard labor in downturns, because they do not want to fire workers who have valuable skills that they will need in the future;

- firms reduce the workweek of capital, because it isn't worth paying a shift premium to get people to work at night or because the capital will depreciate as it is worked more intensively;

- firms shut factories because, in a putty-clay world, the value of the output that can be produced from using the capital doesn't cover the variable costs in terms of labor and materials.

The challenge is to derive a suitable proxy for unobserved output utilization variation,

$\Delta \ln U$. BFK consider a firm that seeks to minimize the present discounted value of costs for any given path of output. There is a convex cost of adjusting the quasi-fixed factors - capital stock

\footnotetext{
${ }^{6}$ See Basu, Fernald, and Kimball (2006) for references.
} 
and number of employees. In addition to this extensive margin, firms have access to various intensive margins: Hours worked per employee; effort required of employees per hour of work; and the workweek of capital (e.g., varying the number of shifts). BFK show conditions in which the relatively easily observed margin (hours per worker) proxy for the two difficult-to-observe margins (labor effort and capital's workweek). In particular, the basic idea behind using growth in hours-per-worker to the regression as a proxy for unobserved variations in labor effort and capital's workweek is that a cost-minimizing firm operates on all margins — whether observed or unobserved-simultaneously. As a result, changes in observed margins can proxy for otherwiseunobserved utilization changes. If labor is particularly valuable, for example, firms will work existing employees both longer (observed hours per worker rise) and harder (unobserved effort rises).

In particular, BFK estimate (with demand-side instruments) the following equation on industry data:

$$
\Delta \ln Y_{i}=\mu_{i} \Delta \ln X_{i}+\beta_{i} \Delta \ln \left(H^{i} / N^{i}\right)+\Delta \ln A_{i}
$$

where

$$
\Delta \ln X_{i}=s_{K i} \Delta \ln K_{i}+s_{L i} \Delta \ln L_{i}+s_{M i} \Delta \ln M_{i} .
$$

$X_{i}$ is revenue-share-weighted inputs of capital, labor, and intermediate-inputs, $M_{i}$. $\ln \left(H^{i} / N^{i}\right)$ is hours/worker (note that total hours, as well as labor quality, is already included in labor input, $L_{i}$ ). The coefficient $\beta_{i}$, which can be estimated, relates observed hours growth to unobserved variations in labor effort and capital's workweek. That coefficient incorporates various elasticities including, in particular, the elasticity of unobserved effort with respect to hours, from the implicit function relating them (which came out of optimization). 
To create a quarterly utilization series, we use the estimated industry $\beta_{i}$ coefficients, applied to quarterly data. We first detrend the data using the Christiano-Fitzgerald bandpass filter to remove components of hours/worker at frequencies lower than 2 and exceeding 32 quarters. We then use the average industry weights from BFK to create an aggregate quarterly utilization measure.

\section{$\underline{\text { Investment versus consumption }}$}

Considerable recent literature looks at the role of "investment-specific technical change," as in Greenwood, Hercowitz, and Krusell (1997). BFFK (2013) argue that a more natural (though equivalent) breakdown is along the lines of equipment investment versus consumption. To allow an analysis along these lines, I use relative prices to decompose aggregate TFP into TFP for the (non-structures, non-residential) investment sector, $I$, and for the consumption sector, C. "Consumption" in this context means everything that isn't in the investment sector, i.e., everything other than private business equipment and intellectual property investment as well as consumer durables.

In particular, we can take aggregate TFP growth (defined in equation 1) as, identically, equal to:

$$
\Delta \ln T F P=w^{I} \Delta \ln T F P^{I}+\left(1-w^{I}\right) \Delta \ln T F P^{C},
$$

where $w^{j}$ is the share of sector $j \in(C, I) .^{7}$ If producers in both sectors have equal factor shares, pay the same factor prices, and have indirect business taxes that are a constant proportion to one another, ${ }^{8}$ then changes in relative TFP equal changes in relative prices:

\footnotetext{
${ }^{7}$ As Basu and Fernald (2002) discuss, there are also reallocation effects related to differences in factor prices across sectors. The data are not available to measure those terms in quarterly data.

${ }^{8}$ Under zero profits, which we maintain, the value of output equals the value of input: $P^{m} Y^{m}=W^{m} L^{m}+R^{m} K^{m}$, where $m \in$ (Investment, consumption). Differentiating logarithmically, assuming equal factor shares in the two sectors, yields: $\Delta \ln Y^{m}-\alpha \Delta \ln K^{m}-(1-\alpha) \Delta \ln L^{m}=\alpha \Delta \ln R^{m}+(1-\alpha) \Delta \ln W^{m}-\Delta \ln P^{m}$.
} 


$$
\Delta \ln T F P^{I}-\Delta \ln T F P^{C}=\Delta \ln P_{C}-\Delta \ln P_{I}
$$

$\Delta \ln P_{I}$ is the prices of equipment and software combined with consumer durables; $\Delta \ln P_{C}$ is the price of business output less the price of investment. ${ }^{9}$ That is, if $\Delta \ln P$ is growth in the price of business output, then $\Delta \ln P_{C}$ is defined implicitly by $\Delta \ln P=\left(1-w^{I}\right) \Delta \ln P_{C}+w^{I} \Delta \ln P_{I}$.

I impose (4) quarter-by-quarter, which is a strong assumption. BFFK find that passthrough of relative technology to relative prices can take years. However, the link between relative TFP and relative prices is closer and faster. Much of the slippage, however, reflects utilization, which drives a gap between measured TFP and technology. BFFK show how to use input-output tables flows to map utilization to final uses.

\section{Data Sources and Implementation}

Detailed discussion of data and implementation is in the appendix. This section provides a high-level summary.

Key data sources for estimating (unadjusted) quarterly TFP for the U.S. business sector are the following:

(i) Hours: The BLS productivity and cost release provides data on $\Delta \ln H$ for the business sector. These data are available from 1947:1 on.

(ii) Output: Output is a weighted average of the income and expenditure sides of the quarterly national income and product accounts (NIPA). NIPA provide explicit data on real and nominal expenditure-side business output. (It is expenditure side because it is defined as expenditure-based GDP less non-business output.) I construct nominal income-side business output by taking gross domestic income and subtracting nominal output of general government and the household sector.

The left-hand-side is measured TFP; the right-hand-side is share-weighted real factor prices. Assuming factor prices are equal in the two sectors implies the equation in the text. Indirect business taxes drive a wedge between producer and purchaser prices but do not affect the relationship as long as log-changes over time are the same in both sectors. See Basu, Fernald, Fisher, and Kimball (2013) for more discussion of the relationship between relative prices and relative technologies.

${ }^{9} \Delta \ln P_{C}$, the price of business output less the price of equipment and consumer durables, is defined implicitly by $\Delta \ln P=w^{C} \Delta \ln P_{C}+w^{I} \Delta \ln P_{I}$. 
Real business income is the nominal value deflated by the expenditure-side business output deflator.

(iii) Capital input: Quarterly capital growth, $\Delta \ln K$, weights growth in 15 disaggregated types of capital using estimated factor payments (which, in turn, use estimated user costs). The quarterly NIPA provide investment data for 5 types of non-residential equipment, 5 types of structures, and 3 types of intellectual property. ${ }^{10}$ I use these data to create perpetual-inventory series on (end of previous quarter, i.e., beginning of current quarter) capital stocks by different type of asset. In addition, the NIPAs provide quarterly data on stocks of inventories. Finally, I interpolate and extrapolate data on land input from the BLS multifactor productivity dataset. Growth in these 15 disaggregated types of capital are weighted using estimated user costs to generate capital input.

(iv) Factor shares: I use NIPA data to construct estimates of total business factor costs as well as payments to labor. Capital payments are then a residual. Following Jorgenson, Gollop, and Fraumeni (1987) and the BLS, cost equals revenue net of taxes on production and imports (TOPI, formerly known as indirect business taxes), plus subsidies, plus the portion of TOPI that is properly allocated to capital (property and motor vehicle taxes). I allocate proprietors' income between labor and capital so that labor's share of non-corporate, non-government businesses matches the share for non-financial corporations. I then interpolate the resulting annual data on factor shares, $\alpha$ and $(1-\alpha)$.

(v) Labor composition: From 1979:1 on, I use quarterly estimates that follow Aaronson and Sullivan (2001), as updated by Bart Hobijn and Joyce Kwok. Those estimates use quarterly data from the Current Population Survey, and do rolling Mincer wage regressions to weight workers by observable skill. Prior to 1979, I interpolate annual data from BLS multifactor productivity data.

(vi) Investment versus consumption technology: To decompose aggregate TFP along final demand lines, I create two Tornquist price indices from NIPA data. The first is the price of "investment," defined as business equipment, intellectual property, and consumer durables. (As shorthand, I will sometimes refer to this as "equipment" TFP.) The second is the price of non-durable "consumption," defined as the price of business output less the price of equipment. I assume the relative price of investment corresponds, quarter-by-quarter, to TFP in consumption relative to equipment investment.

To estimate a quarterly series on utilization, the key data source is the following:

(vii) Industry and aggregate utilization: Hours-per-worker $\left(H^{i} / N^{i}\right)$ by industry from the monthly employment report of the BLS. These are used to estimate a series on industry utilization $\Delta \ln U_{i}=\beta_{i} \Delta \ln \left(H^{i} / N^{i}\right)$, where $\beta_{i}$ is a coefficient estimated by BFFK. I then calculate an aggregate utilization adjustment as

\footnotetext{
${ }^{10}$ Prior to 1958 , the NIPA accounts provide only a single aggregated measure of quarterly structures investment.
} 
$\Delta \ln U=\sum_{i} w_{i} \Delta \ln U_{i}$, where $w_{i}$ is the industry weight from BFK (taken as the average value over the full sample). ${ }^{11}$

(viii) Investment and consumption utilization: I use input-output data from Basu, Fernald, Fisher, and Kimball (2013). They suggest that a reasonable measure of equipment investment utilization change is $\Delta \ln U^{I}=\left[\begin{array}{lll}b_{J, 1} & b_{J, 2} & \ldots\end{array}\right]^{\prime}[I-B]^{-1}\left[\begin{array}{lll}\Delta \ln U_{1} & \Delta \ln U_{2} & \ldots\end{array}\right]^{\prime}$ :

- $\left[\begin{array}{lll}b_{J, 1} & b_{J, 2} & \ldots\end{array}\right]$ is a row vector of commodity shares of equipment investment and consumer durables. For example, if commodity 1 were electrical equipment, then $b_{J, 1}$ would be the share of electrical equipment in total equipment investment and consumer durables).

- $\mathrm{B}$ is the intermediate-input shares from the use matrix (where element $b_{i j}$ is the share of commodity $j$ in industry $i$ ).

- $\left[\begin{array}{lll}\Delta \ln U_{1} & \Delta \ln U_{2} & \ldots\end{array}\right]^{\prime}$ is the vector of industry utilization changes.

For the industry weights, $\left[\begin{array}{lll}b_{J, 1} & b_{J, 2} & \ldots\end{array}\right]^{\prime}[I-B]^{-1}$, I use the average value over the BFFK sample of 1961-2005. Consumption ("other") utilization is implicitly defined by the assumption that total utilization change is a share-weighted average of utilization in equipment investment and consumption, so that $\Delta \ln U^{C}=\left(\Delta \ln U-w^{I} \Delta \ln U^{I}\right) /\left(1-w^{I}\right)$.

As already noted, the resulting series differs conceptually from the BFK purified technology series along several dimensions. BFK use detailed industry data to construct estimates of industry technology change that control for variable factor utilization and deviations from constant returns and perfect competition. They then aggregate these residuals to estimate aggregate technology change. Thus, they do not assume the existence of a constant-returns aggregate production function. The industry data needed to undertake the BFK estimates are available only annually, not quarterly. As a result, the quarterly series estimated here does not control for deviations from constant returns and perfect competition. ${ }^{12}$

As BFK (and, earlier, Basu and Fernald, 1997) argue, even if the typical industry has close to constant returns, there is substantial heterogeneity across industries, and this heterogeneity generates reallocation terms that have aggregate implications and that affect

$11 w_{i}=w_{i}^{V} /\left(1-s_{M i}\right)$, where $w_{i}^{V}$ is the industry's weight in aggregate value added, and $s_{M i}$ is the share of intermediate inputs.

${ }^{12}$ The output data also differ, both in vintage and data source, from the annual data used by BFK. 
estimates of aggregate dynamics. The quarterly series here does not control for these aggregate reallocation terms.

\section{Comparison to the BLS MFP data}

The chart below shows that the annualized growth rate in the quarterly TFP series (without the utilization-adjustment) is very close to the growth rate of the BLS Multifactor Productivity measure for the private business sector. ${ }^{13}$ The BLS measure is only available annually. The correlation between annual changes in the two series is 0.97 .

\section{Comparing BLS MFP and (annual) Fernald TFP}

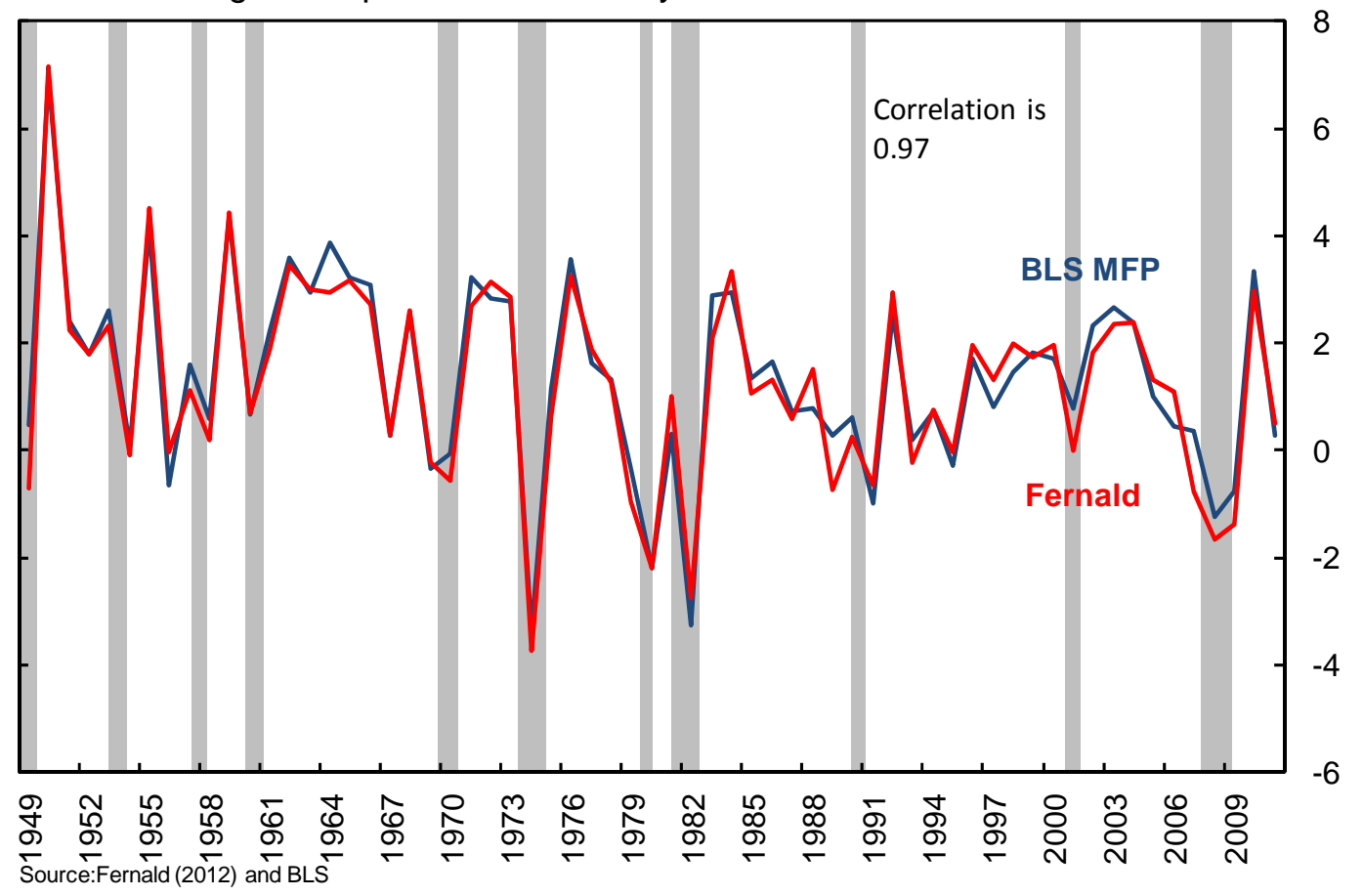

${ }^{13}$ Note that annualizing the quarterly series is not the same as averaging the four quarterly growth rates, which would create a Q4/Q4 measure. Instead, I summed the quarterly growth rates to create a log-levels index; took exponents to create a level; averaged the levels during the four quarters of each year; and then took growth rates of this annual levels index. It is readily verified numerically that this is very close to a seven quarter moving average of growth rates with "tent weights", where the weights from Q2 of year $T-1$ to Q4 of year $T$ are 1/16, 2/16, $3 / 16,4 / 16,3 / 16,2 / 16,1 / 16$. 
There are a number of minor differences between the two series. Some of these differences reflect what can be done quarterly versus annually. For a review of the methodology and history of the BLS measures, see Dean and Harper (2001) and BLS (2007). To summarize some of the differences:

(i) BLS covers private business, the Fernald quarterly database covers total business.

(ii) BLS uses expenditure-side measures of output, whereas Fernald combines income and expenditure-side measures of output.

(iii) BLS assumes hyperbolic (rather than geometric) depreciation for capital.

(iv) Fernald does not include rental residential capital. (My hope is to add this at a later date.)

(v) BLS uses the more disaggregated investment data available at an annual frequency (42 types of equipment and software, 21 types of nonresidential structures, 9 types of residential capital, multiple types of inventories, and land).

(vi) The BLS and Hobijn-Kwok estimates of labor quality differ somewhat.

\section{Conclusion}

This note describes a new quarterly growth-accounting dataset that, following established growth-accounting conventions, controls for heterogeneity in capital and labor input. The dataset also implements an adjustment for variations in factor utilization — an important highfrequency, non-technological source of fluctuations in standard measures of TFP.

Note that the quarterly data do not necessarily control for all non-technological sources of TFP fluctuations. In particular, they do not control for non-constant returns to scale or reallocations of resources across uses with different marginal products. Basu, Fernald, and 
Kimball (2006) control for these additional factors in annual data. However, the quarterly utilization-adjusted series goes a long way towards cleansing the Solow residual of nontechnological cyclicality. 


\section{Appendix: Details on Data and Variable Construction}

\section{Output}

NIPA tables 1.3.5 and 1.3.6 (gross value added by sector) provide data on nominal and real business-sector output. That is the measure of output that is also reported in the BLS productivity and cost release, and corresponds to the expenditure side of the national accounts. Specifically, it is measured as GDP less non-business output. To measure nominal business income, I take nominal gross domestic income and subtract nominal household and general government expenditure (also from Table 1.3.5). That correctly imposes that the statistical discrepancy (the difference between GDP and GDI) arises from the business sector alone. ${ }^{14} \mathrm{I}$ then deflate GDI with the business deflator. An equivalent way to measure this is to define $\Delta \ln$ (Nominal Gap) as the difference in (log) growth rates between nominal business expenditure and nominal business income. Then we can measure real business income as:

$$
\Delta \ln Y^{\text {Business,Income }} \equiv \Delta \ln Y^{\text {Business, Expenditure }}+\Delta \ln (\text { Nominal Gap) } .
$$

To avoid taking a strong stand on which measure is more reliable, I weight them equally. Hence, business output growth is:

$$
\Delta \ln Y^{B u \sin e s s}=0.5 \cdot \Delta \ln Y^{\text {Business,Expenditure }}+0.5 \cdot \Delta \ln Y^{\text {Business, Income }}
$$

\section{Hours}

The BLS productivity and cost release provide business-sector hours worked for each quarter. The data begin in 1947:1, and new data are available approximately five weeks after the

\footnotetext{
${ }^{14}$ The main non-business categories of general government and the service flow from owner-occupied housing do not contribute to the statistical discrepancy. General government output is inherently measured using income flows. And the service flow from owner-occupied housing is imputed, which means there are not separate income and expenditure measures. (One can easily confirm that household and general government gross value added, from NIPA Table 1.3.5, less their consumption of fixed capital, from Table 1.7.5, matches their national income from Table 1.13.)
} 
end of each quarter. Since this is shortly after the advance NIPA release, it is then possible to produce an estimate of the quarterly TFP series. The BLS itself produces an annual TFP series, but only with a sizeable lag.

\section{Capital Input}

Capital input aggregates heterogeneous capital goods into a single service-flow-weighted index of productive services, $K$. I create quarterly estimates of the stocks of 15 types of capital, including five categories of equipment and software; five categories of structures; three categories of intellectual property products (IPP); inventories; and land. For equipment, software, IPP, and structures, I use detailed quarterly investment data, $I_{j}$, with assumed (annual) geometric depreciation rates, $\delta_{j}$, in parentheses: ${ }^{15}$

${ }^{15}$ For equipment and structures, investment data are from NIPA Tables 5.3.5 (nominal) and 5.3.6 (chainweighted). Prior to 1958, I use aggregate structures investment. Inventory data are from NIPA Tables 5.7.5B and 5.7.6B. 


\begin{tabular}{|l|r|}
\hline \multicolumn{1}{|c|}{ Type of capital } & $\begin{array}{r}\text { Deprec.rate } \\
\text { (ar, percent) }\end{array}$ \\
\hline Equipment (avg., weighted by cap. stocks) & 13.0 \\
\hline 1. Computers and peripheral equipment & 31.5 \\
\hline 2. Other information processing equipment ${ }^{16}$ & 13.4 \\
\hline 3. Industrial equipment & 9.3 \\
\hline 4. Transportation equipment & 12.8 \\
\hline 5. Other equipment & 13.9 \\
\hline Structures (avg., weighted by cap. stocks) & 2.6 \\
\hline 6. Commercial and health care & 2.5 \\
\hline 7. Manufacturing & 3.1 \\
\hline 8. Power and communication & 2.2 \\
\hline 9. Mining exploration, shafts, and wells & 2.8 \\
\hline 10. Other structures & 2.1 \\
\hline Intellectual Property Capital (avg., weighted by cap. stocks) & $15.8^{17}$ \\
\hline 11. Software & 46 \\
\hline 12. Research \& Development & 15 \\
\hline 13. Artistic (Entertainment, literary, and artistic originals) & 10 \\
\hline
\end{tabular}

Source: Fraumeni (1997) provides estimates of geometric depreciation rates for 31 types of equipment and 15 types of structures. I use BEA, 2004, for medical and nonmedical instruments. BEA (2013) provides depreciation rates for a range of artistic investments. For $\mathrm{R} \& \mathrm{D}$, there are a wide range of empirical estimates in the literature; 15 percent is a fairly traditional estimate (see, e.g., Hall 2010, who attributes it to Zvi Griliches). (Hall, 2010, and Li, 2012, discuss the challenges and uncertainties around these estimates.) From these highly disaggregated depreciation values, I aggregate to the level of detail available quarterly by weighting with the estimated nominal value of the stock of capital of each detailed type.

For the categories of equipment and software and for structures, I calculate beginning-ofquarter (end of previous quarter) capital stocks $K_{j, t-1}$ using the perpetual inventory method, so

\footnotetext{
${ }^{16}$ Other includes communication equipment, medical equipment and instruments, nonmedical instruments, photocopy and related equipment, and office and accounting equipment.

${ }_{17}$ Average since 1959:1, when software investment becomes available. The average from 2000:1 through 2013:Q2 is 20.1 percent.
} 
that $K_{j, t}=\left(1-\delta_{j}\right) K_{j, t-1}+I_{j, t-1}$. As an initial estimate of the capital stock, I use end-of-year BEA estimates of the stock of each type of capital as of the end of 1946 (i.e., beginning of 1947:1).

For land, I interpolate the annual estimates from the BLS MFP database. ${ }^{18}$ After the end of the BLS sample, I extrapolate assuming the annual values follow an AR(1) process). Since land use is a smooth and slow moving series, the approximation error from the interpolation is likely to be small.

To go from disaggregated capital stocks to a composite capital input measure, the standard first-order conditions for firm optimization imply that we need to weight by service flows. Implicitly, the nominal value of the service flow from a given type of capital $j$ depends on the user $\operatorname{cost} R_{j}$ of that type of capital multiplied by the stock of that type of capital, i.e., $R_{j} \cdot K_{i}$.

Standard first-order conditions for capital imply that the user cost is $R_{j t}=\left(i_{t}+\delta_{j}-\pi_{j t+1}^{e}\right) P_{j t}^{I}$,

where $i$ is the nominal interest rate, $\pi_{j t+1}^{e}$ is the expected rate of price appreciation for asset $j$

between today and next period, and $P_{j}^{I}$ is the purchase price (investment price) for asset $j$.

Given an estimate of the user costs, the Tornquist index of the service flow from aggregate capital input is defined as:

$$
\Delta \ln K=\sum_{j} \frac{\left[s_{j}(t)+s_{j}(t-1)\right]}{2} \cdot \Delta \ln K_{j}
$$

where the nominal shares in each period are $s_{j}=\frac{R_{j} \cdot K_{j}}{\sum_{j}\left(R_{j} \cdot K_{j}\right)}=\frac{\left(r+\delta_{j}-\pi_{j}^{e}\right) \cdot P_{j}^{I} \cdot K_{j}}{\sum_{j}\left(r+\delta_{j}-\pi_{j}^{e}\right) \cdot P_{j}^{I} \cdot K_{j}}$.

${ }^{18}$ Calculated from capital tables.xls obtained from http://www.bls.gov/mfp/mprdload.htm (originally downloaded May 7, 2007 but updated as new tables become available each year). The BLS has separate tables on an SIC basis and NAICS basis (which start in 1987). I splice the land-input series together using growth rates, so that land input growth from 1948-1987 is from the SIC data, and from 1987 on is from the NAICS data. 
To calculate the user cost, we need measures of expected asset-specific price appreciation $\pi_{j t+1}^{e}$ as well as a nominal interest rate series. I estimated expected asset-price inflation using a centered 16-quarter moving average of price changes. ${ }^{19}$ This approach weights the recent past equally with the actual (unknown, but expected) future and has the a priori desirable property that asset weights $s_{J}$ are relatively smooth from quarter to quarter. At the same time, these weights retain the genuine low-frequency movements in the data.

I would note that I experimented with several sometimes-used alternative methods of obtaining expected price appreciation that have some disadvantages. First, under rational expectations, actual inflation (between periods $t$ and $t+1$ ) should equal ex ante expected inflation plus white noise error. This reasoning suggests that it should be reasonable to simply use actual asset inflation as our estimate of expected inflation. Unfortunately, since ex post asset inflation is volatile, this measure leads to implausibly volatile shares $s_{J}$ from quarter to quarter. Second, I estimated a simple univariate autoregressive forecasting model of the asset price and used the fitted values. This led to smoother shares, but had the undesirable feature that the forecasting model changed each time the data was updated-leading to minor but undesirable revisions in capital input over the historical period. Moreover, it is implausible that agents knew the full-period model; and using a recursive method (i.e., where only observations up through period $t$ were used to forecast asset inflation for period $t+1)$ implied having very few observations in the early years.

For the nominal interest rate, a reasonable benchmark is zero profits, so that all residual factor payments go to capital. There is then some implicit rate of return $i$ such that the sum of factor payments is equal to output. As a residual, capital compensation is $P_{K} K=\alpha C O S T$, where

\footnotetext{
${ }^{19}$ At the end of the sample, I drop the future observations since they are obviously not observed.
} 
capital's share $\alpha$ and COST are discussed below. This compensation, in turn, equals the sum of payments to the different types of capital: $K_{\text {comp }}=\sum_{j} R_{j} \cdot K_{\text {input }, j}=\sum_{j}\left(i+\delta_{j}-\pi_{j}\right) \cdot P_{j}^{I} \cdot K_{j}$. This equation implicitly defines the nominal interest rate $i: \quad K_{\text {comp }}=i \cdot \sum_{j} P_{j}^{I} \cdot K_{j}+\sum_{j}\left(\delta_{j}-\pi_{j}\right) \cdot P_{j}^{I} \cdot K_{j}$, or

$$
i=\frac{K_{c o m p}-\sum_{j}\left(\delta_{j}-\pi_{j}\right) \cdot P_{j}^{I} \cdot K_{j}}{\sum_{j} P_{j}^{I} \cdot K_{j}} .
$$

Once we have a measure of the nominal interest rate $i$, we can calculate the user costs and relative weights for each of the types of capital. We can then calculate the growth in the index of capital input, giving us the key information necessary to map quarterly labor productivity into quarterly TFP.

\section{Factor Shares}

I use NIPA data to calculate annual factor shares for labor and capital in business cost, and then interpolate to quarterly with a cubic spline. ${ }^{20}$ One question is what to include in business cost, and a second is what to include in labor compensation. ${ }^{21}$

In terms of cost (the denominator), the gross value added of business (from Table 1.3.5) includes indirect business taxes, now known as taxes on production and imports, or TOPI. Sales and excise taxes, included in TOPI, are not revenue received by the business at all. Hence, in a standard cost-minimizing framework for the firm, they are irrelevant. ${ }^{22}$ However, some elements

\footnotetext{
${ }^{20}$ If implicit contracts are important, then the observed fluctuations in factor payments might not reflect actual fluctuations. Indeed, the business-cycle fluctuations in factor shares might not be allocative at all, arguing for simply assuming Cobb-Douglas and using constant factor shares.

${ }^{21}$ See Elsby, Hobijn, and Sahin (2013) for extensive discussion of the challenges in measuring factor shares.

${ }^{22}$ Gomme and Rupert (2004) take a different view and label these taxes as "ambiguous income."
} 
of TOPI are associated with the use of specific types of capital, namely property taxes and motor-vehicle taxes. As is standard in the growth accounting literature, we allocate those portions of TOPI to capital costs. ${ }^{23}$ Hence, business cost is the gross value added of businesses, net of business TOPI other than the property and motor vehicle taxes.

The second major challenge is the numerator of labor or capital cost. Here, the challenge is proprietors' income, which is the earnings of owners of non-corporate businesses, and which combines a return to the labor and capital provided by that owner. I resolve this challenge with the operational assumption that private, non-corporate businesses have the same factor shares as non-financial corporations.

To understand the challenge, consider a plumber who operates as a sole proprietor. She earns a return net of his costs, which is compensation for providing her time as well as a return on the capital invested in her plumbing truck and specialized tools. Such mixed income amounts to about 10 percent of business factor costs (averaged 1948-2012). Entrepreneurs and smallbusiness owners on average appear to earn below-market returns (e.g., Hamilton, 2000), and the evidence suggests they are willing to do so because of non-pecuniary benefits (flexibility, not having a boss, and so on; see Hurst and Pugsley, 2011). Allocating proprietors' income thus requires allocating the non-pecuniary benefits between a low implicit wage and a below-market return on the plumbing truck in our example. This is a challenging problem, since the proprietor cares about the total returns to their joint provision of capital and labor, not how those returns are allocated.

\footnotetext{
${ }^{23}$ The challenge here is that the split between business and non-business property and motor-vehicle taxes is not published. The BLS MFP dataset uses unpublished BEA data on the split. Correspondence with BEA staff indicates that the business portion is well approximated by using half of property taxes plus motor vehicle taxes from NIPA Table 3.5.
} 
I resolve the challenge by assuming that factor shares for private non-corporate businesses match factor shares for non-financial corporations. ${ }^{24}$ This is relatively straightforward to calculate (subject to important nuances below) and does not require strong/arbitrary assumptions about wages and capital returns of proprietors. Note that using the same factor shares is not just a matter of multiplying just proprietors' income by the shares for non-proprietors. The reason is that some factor payments for noncorporate businesses are already accounted for. For example, proprietors' consumption of fixed capital (a capital cost) is explicitly accounted for, as is compensation paid to their employees (a labor cost). However, the NIPA tables provide sufficient details to derive a measure of factor cost for private noncorporate businesses, which can then be allocated using the corporate shares.

One alternative, as in the BLS productivity and cost release, is to assume proprietors earn the average wage in the economy. That approach is inconsistent with the evidence that the typical proprietor earns less than their predicted wage. For their annual MFP data, the BLS takes a different approach. They estimate a market wage for self-employed and unpaid family workers based on worker characteristics, and they estimate a market return to capital to match the return on corporate capital. Since these estimated payments to proprietors' labor and capital would exceed actual proprietors' income, they scale down both wages and the nominal rate of return on capital proportionately to match proprietor's income. This method “treats any apparent excess or deficiency in corporate income neutrally with respect to labor and capital" (BLS 2007, footnote 9, page 13). The MFP approach is data intensive, and since the nominal interest rate is constrained to be positive, it limits the degree to which losses are allowed.

\footnotetext{
${ }^{24}$ This is not the same as assuming the entire non-corporate sector matches the non-financial corporate sector, because government enterprises are part of the non-corporate business sector as well.
} 
I would note several other differences relative to the MFP calculation of factor shares. ${ }^{25}$ First, the MFP data assume that capital in the financial sector earns an exogenous return, since they consider the implicit nominal return to capital (the return in the user cost formula that just exhausts factor payments) in the financial sector to be unreasonably high. Rather than arbitrarily adjust factor payments for one sector, I simply take the NIPA data as given. ${ }^{26}$ Second, the MFP data seek to match nominal output from the expenditure side of the national accounts, whereas data on factor payments come from the income side. The MFP data resolve this by including the statistical discrepancy to capital income. The BLS assumes that the statistical discrepancy comes entirely from capital payments, so they add the statistical discrepancy to gross operating surplus. A priori, it is not obvious that the statistical discrepancy is entirely a matter of capital income such as corporate profits. ${ }^{27}$ Even in terms of expenditure, an alternative and relatively agnostic assumption is that the statistical discrepancy is distributed according to factor cost. In addition, my measure of output weights both the income and expenditure sides equally. Hence, I do not allocate the statistical discrepancy.

\section{Utilization}

The disaggregated BLS hours-per-worker data necessary to make the BFK adjustment are available quarterly (or even monthly), matching our needs. I assume that the coefficients on

${ }^{25}$ The BLS methodology is described in Harper et al (2008)—see especially their appendix. A helpful BEA-BLS spreadsheet for selected years is available at

http://www.bea.gov/about/pdf/relation_of_nipa_gdp_to_bls_private_sector_current_dollar_output.pdf. There are several more minor differences between my numbers and the BLS, where they use unpublished data, but these do not appear to be quantitatively important.

${ }^{26}$ Basu, Inklaar, and Wang (2011) argue that the apparently excessive internal rate of return in finance (which leads to a low apparent labor share in finance) reflects a misallocation of value added (and, hence, gross operating surplus) between the financial sector and other sectors of the economy. In particular, a large portion of this apparently excessive financial capital return should properly be allocated to capital returns of other businesses.

${ }^{27}$ For example, proprietors' income affects both capital and labor, and is surely mismeasured (see NIPA Table 7.14 for a statement of the sizeable BEA imputation for underreporting on income tax returns). 
hours-per-worker growth, at a quarterly frequency, match the annual BFK coefficients. This allows me to estimate a quarterly utilization adjustment that, when annualized, is extremely close to the BFK adjustment. ${ }^{28}$

There are a number of technical details. First, we need a full panel of estimates of industry hours per worker. This requires merging BLS data on hours per worker on an SIC basis (which were discontinued in April, 2003) with more recent data on a NAICS basis. The BFK estimates used SIC classifications, so we generally use the NAICS data to extrapolate the SIC data beyond 2002. We also need to estimate some series for the earlier years. In particular, the SIC data for construction and manufacturing industries are generally available as of 1947 (sometimes earlier); much of the non-manufacturing, non-construction data begin only in 1964 or, in some cases, even later. BFK-augmented values that aren't available from the BLS with annual data from Dale Jorgenson; since these data are not available quarterly, we instead use the available industry data to extrapolate series backwards. More specifically:

- In the BLS data, hours data for both instruments and electrical equipment begin only in 1988; from 1988-2003, the correlation of hours in industrial machinery with hours in electrical equipment is above 0.9 , and the correlation with instruments is above 0.8 . Hence, for the 1988-2003 period, I project hours per worker in both electrical equipment and in instruments on hours per worker in industrial machinery, and then use the fitted values back to 1947 . In addition, there is also no separate instruments industry in the NAICS data (it is part of electronics), so we extend the instruments category with data on computer and electronic products.

\footnotetext{
${ }^{28}$ There are some nevertheless some differences. For example, in some cases, BLS data are not available for the full sample period or for all detailed industries; in those cases, BFK augmented the BLS data with annual estimates provided by Dale Jorgenson. Those data are not available quarterly, necessitating different adjustments. Nevertheless, the utilization estimate is extremely close to the BFK estimate.
} 
- For transportation, information (i.e., communications), and utilities, there are disaggregated NAICS data back to either 1964 or 1972, but only aggregated SIC data back to 1964 . In those cases, we take the NAICS data as our primary dataset and backcast with the SIC data.

- Even on an SIC basis, data for most service industries begin only in 1964 . We extract three principal components from the construction and manufacturing industries (22 total industries), and then project service hours on these principal components. For the earlier period, the fitted values from these projections provide an estimate of quarterly hours per worker for all industries.

Second, I bandpass filter the log of the quarterly hours-per-worker data by industry to obtain frequencies between 8 and 32 quarters, I then take first differences and multiply by the estimated industry utilization coefficient from BFK. This gives industry estimates of utilization change. I use annual weights from BFK to aggregate across industries. For the period before 1949, I use the 1949 values; similarly, after 1996, I use the 1996 values. $^{29}$

Third, we use coefficients estimated in BFK to create an industry utilization series. Finally, we use annual BFK industry weights to aggregate.

${ }^{29}$ BFK bandpass filter annual rather than quarterly data, which leads to a slight difference in the estimated trend and, hence, in the estimated utilization series. 


\section{References}

Aaronson, Daniel and Daniel Sullivan (2001). "Growth in Worker Quality." Economic Perspectives, Federal Reserve Bank of Chicago.

Basu, Susanto, and John Fernald (1997). Returns to Scale in U.S. Manufacturing: Estimates and Implications. Journal of Political Economy, April 1997.

Basu, Susanto, and John Fernald (2001). "Why Is Productivity Procyclical? Why Do We Care? In New Directions in Productivity Analysis. Studies in Income and Wealth Vol. 63, ed. by Dean, Harper, and Hulten :: Chicago: University of Chicago Press, 2001.

Basu, Susanto, and John Fernald (2002). "Aggregate Productivity and Aggregate Technology.”European Economic Review, June 2002

Basu, Susanto, John Fernald, and Miles Kimball (2006). “Are Technology Improvements Contractionary?" American Economic Review.

Basu, Susanto, John Fernald, Jonas Fisher, and Miles Kimball (2013). "Sector-Specific Technical Change." Manuscript

Basu, Susanto, Robert Inklaar, and J. Christina Wang (2011). "The value of risk: measuring the service output of US commercial banks." Economic Inquiry 49 (1), 226-245.

Bureau of Economic Analysis (2004). "BEA Depreciation Estimates.” Downloaded from www.bea.gov/national/FA2004/Tablecandtext.pdf.

Bureau of Labor Statistics (2007). "Technical Information About the BLS Multifactor Productivity Measures." http://www.bls.gov/mfp/mprtech.pdf.

Bureau of Labor Statistics (2009). "Historical multifactor productivity measures (SIC 1948-87 linked to NAICS 1987-2008)."

ftp://ftp.bls.gov/pub/special.requests/opt/mp/prod3.mfptablehis.zip (downloaded June 26, 2009.)

Corrado, Carol, Charles Hulten, and Daniel Sichel (200x).

Corrado, Carol; Jonathan Haskel, Cecilia Jona-Lasinio and Massimiliano Iommi, (2012)., Intangible Capital and Growth in Advanced Economies: Measurement Methods and Comparative Results." Working Paper (June), available at http://www.intan-invest.net

Dean, Edwin R. and Michael J. Harper (2001). "The BLS Productivity Measurement Program," In New Directions in Productivity Analysis. Studies in Income and Wealth Vol. 63, ed. by Dean, Harper, and Hulten :: Chicago: University of Chicago Press, 2001.

Elsby, Michael W. L., Bart Hobijn, and Ayşegül Şahin (2012). "The Decline of the U.S. Labor Share." Manuscript prepared for Brookings Panel on Economic Activity, September 1920,2013 
Fisher, Jonas D.M.(2006) . "The Dynamic Effects of Neutral and Investment-Specific Technology Shocks," Journal of Political Economy, University of Chicago Press, vol. 114(3), pages 413-451, June

Fraumeni, Barbara M. (1997). "The Measurement of Depreciation in the U.S. National Income and Product Accounts." Survey of Current Business, July.

Gomme, Paul and Peter Rupert (2004). "Measuring Labor's Share of Income.” Policy Discussion Papers, Federal Reserve Bank of Cleveland.

Greenwood, Jeremy , Zvi Hercowitz and Per Krusell (1997). "Long-Run Implications of Investment-Specific Technological Change.” The American Economic Review, Vol. 87, No. 3 (Jun., 1997), pp. 342-362.

Hall, Bronwyn (2010). "Measuring the Returns to R\&D: The Depreciation Problem." Contributions in Memory of Zvi Griliches, Jacques Mairesse and Manuel Trajtenberg, editors (p. 341 - 381).

Hamilton, B. (2000). "Does Entrepreneurship Pay? An Empirical Analysis of the Returns to Self Employment". Journal of Political Economy, 108(3), 604-31.

Harper, Michael J., Brent R. Moulton, Steven Rosenthal, and David B. Wasshausen (2008). "Integrated GDP-Productivity Accounts." Manuscript, BLS,

Hulten, Charles R. (1978). "Growth Accounting with Intermediate Inputs," Review of Economic Studies, Vol. 45, No. 3, October 1978, pp. 511-518.

Hurst, Eric and Benjamin Wild Pugsley (2011). “What Do Small Businesses Do?” Brookings Papers on Economic Activity, 2011.

Li, Wendy (2012).

Nalewaik, Jeremy J. (2011). "The Income- and Expenditure-Side Estimates of U.S. Output Growth-An Update through 2011 Q2," Brookings Papers on Economic Activity, vol. 2, pp. 385-402. 